UDC 347.4

LBC 67.404

\title{
ABUSE OF THE RIGHT TO PROTECTION IN INTELLECTUAL PROPERTY
}

\author{
Olga S. Avdonina
}

Moscow Academy of Economics and Law, Moscow, Russian Federation

Introduction: the article deals with the questions of differentiation of abuse of the right to protection of intellectual property and the fair implementation of the civil rights. The author proposes that the rules of recognition of the abuse of the right to protection of a trademark should be applied to other protected results of intellectual property. The rules on the prohibition of unfair behavior and abuse of the right are primarily addressed to the court. It is important that nowadays the possibility of the qualification by the court of the actions of a person as the abuse does not depend on whether the other side referred to the abuse of the right by the counterpart. The court is entitled to refuse the protection of the rights of the person abusing them. The aim of the study of the author in the work of civil nature is to investigate the bounds of the fair protection of the exclusive rights. The methods used are the following: the methods of systematization, analysis and comparative and legal one. The results: the author's position proved by the study is based on the law and the competent scientific community's opinion of the extent of understanding the right to the protection of the exclusive rights. On the basis of the legal analysis of the provisions of the Civil Code and legal precedents, the differentiation of good faith and abuse of the exclusive right has been made. The conclusions: as a result of the study the author has proposed that the rules of recognition of the abuse of the right to protection of a trademark should be applied to other protected results of intellectual property.

Key words: protection of intellectual property rights, abuse of rights, exclusive right to a trademark, intellectual property, fair and unfair behavior.

УДК 347.4

ББК 67.404

\section{ЗЛОУПОТРЕБЛЕНИЕ ПРАВОМ НА ЗАЩИТУ В СФЕРЕ ИНТЕЛЛЕКТУАЛЬНОЙ СОБСТВЕННОСТИ}

\author{
Ольга Сергеевна Авдонина
}

Московская академия экономики и права, г. Москва, Российская Федерация

\begin{abstract}
Введение: в статье рассмотрены вопросы разграничения злоупотребления правом на защиту интеллектуальной собственности и добросовестной реализации гражданских прав. Предлагается распространить правила признания злоупотреблением правом на защиту товарного знака на иные охраняемые результаты интеллектуальной деятельности. Нормы о запрете недобросовестного поведения и злоупотребления правом адресованы в первую очередь суду. Важно, что сегодня возможность квалификации судом действий лица как злоупотребления не зависит от того, ссылалась ли другая сторона спора на злоупотребление правом противной стороной. Суд вправе по своей инициативе отказать в защите права лицу, злоупотребляющему им. Автором в работе цивилистического характера поставлена цель исследования границ добросовестной защиты исключительных прав. Методы: методологическую основу данного исследования составляет совокупность методов научного познания, сре- ди которых основное место занимают методы системности, анализа и сравнительно-правовой. Результаты: обоснованная в работе авторская позиция опирается на законодательство и мнения компетентной научной среды по вопросу о границах понимания права на защиту исключительного права. На основании правового анализа норм ГК и судебной практики проводится дифференциация добросовестности и злоупотребления исключительным правом. Выводы: в результате исследования предлагается распространить правила признания злоупотреблением правом на защиту товарного знака на иные охраняемые результаты интеллектуальной деятельности.

Ключевые слова: защита интеллектуального права, злоупотребление правом, исключительное право на товарный знак, интеллектуальная собственность, добросовестное и недобросовестное поведение.
\end{abstract}




\section{Введение}

С дореволюционного периода ученые спорят, должно ли быть у права назначение. И.А. Покровский высказал свое критическое мнение в отношении теорий о наличии у субъективного гражданского права некоего «назначения», в частности, теории Л. Дюги [6]. Однако сегодня в гражданском праве последние изменения ГК РФ возвращают нас к идее о назначении гражданского права, которое в некоторых случаях влечет необходимость и/или возможность отказать в реализации субъектом своего права в случае несоответствия результата такой реализации назначению права. Речь идет о добросовестной реализации права лицом, которое по решению суда может быть лишено защиты.

\section{Отказ в защите}

\section{интеллектуального права}

В сфере интеллектуальной собственности данный подход, например, реализован в отношении защиты права на товарный знак [2]. Согласно действующему законодательству лицу, на имя которого зарегистрирован товарный знак [4], не может быть отказано в его защите (даже если в суд представляются доказательства неправомерности регистрации товарного знака) до признания предоставления правовой охраны такому товарному знаку недействительной в порядке, предусмотренном ст. 1512 ГК РФ, или прекращения правовой охраны товарного знака в порядке, установленном ст. 1514 ГК РФ. Однако в судебной практике на уровне постановлений пленумов ВАС РФ и ВС РФ указано, что «суд вправе отказать лицу в защите его права на товарный знак на основании ст. 10 ГК РФ, если по материалам дела, исходя из конкретных фактических обстоятельств, действия по государственной регистрации соответствующего товарного знака могут быть квалифицированы как злоупотребление правом» [1].

Применяя это разъяснение, подчеркивает Э.П. Гаврилов, необходимо иметь в виду следующие обстоятельства. Во-первых, такое решение суда может приниматься лишь при наличии «злоупотребления правом», то есть умышленных действий владельца товар- ного знака, нарушающих основные начала гражданского права и конкретные нормы гражданского законодательства. Во-вторых, решение суда ограничивается отказом в удовлетворении исковых требований, но не влечет прекращения или аннулирования исключительного права [1].

\section{Разграничение добросовестного и недобросовестного поведения на практике}

В то же время в законодательстве и на практике нередки ситуации, когда судам приходится отграничивать случаи добросовестного поведения от недобросовестного [1].

Так, ВС РФ указал, что заслуживает внимания при применении ст. 10 ГК РФ к спорам в отношении субъективных прав на результаты интеллектуальной деятельности и приравненные к ним средства индивидуализации наличие презумпции разумности и добросовестности участников гражданских правоотношений [1]. При решении вопроса о возможности защиты права на средство индивидуализации суд должен учесть цель регистрации товарного знака, реальное намерение правообладателя его использовать, причины неиспользования. В случае же установления того, что правообладателем был зарегистрирован товарный знак не с целью его использования самостоятельно или с привлечением третьих лиц, а лишь с целью запрещения третьим лицам использовать соответствующее обозначение, в защите такого права указанному лицу судом может быть отказано. Таким образом, фактическое неиспользование товарного знака после его регистрации с одновременным судебным преследованием третьих лиц является нарушением ст. 10 ГК РФ, а также ст. 10.bis Парижской конвенции об охране промышленной собственности от 20 марта 1883 года [3].

В то же время тот же ВС РФ выработал позицию, согласно которой действия правообладателя по защите исключительного права на товарный знак не являются злоупотреблением правом, если они совершены до обращения третьего лица в суд с требованием о досрочном прекращении правовой охраны данного товарного знака [1]. Следовательно, не 
может быть отказано в защите исключительного права на товарный знак, в частности, до момента прекращения правовой охраны этого товарного знака, в том числе на основании принятого в соответствии со ст. 1486 ГК РФ решения о досрочном прекращении правовой охраны товарного знака в связи с его неиспользованием [5].

Анализ правоприменительной практики тем самым показывает, что назрела необходимость закрепить в законе более четкие границы добросовестного осуществления исключительных прав, опираясь на созданные в практике подходы. Как представляется, никакое решение суда, как бы удачно оно ни оказалось, не будет иметь того авторитета, каким обладала бы норма, установленная законом.

В то же время, полагаем, следует также распространить позиции, сложившиеся в отношении злоупотреблений в сфере средств индивидуализации, на иные охраняемые результаты интеллектуальной деятельности, что не всегда очевидно для суда [7]. Хотя в Постановлении Пленума Верховного Суда РФ от 23 июня 2015 г. № 25 «О применении судами некоторых положений раздела I части первой Гражданского кодекса Российской Федерации» указано, что поведение одной из сторон может быть признано недобросовестным по инициативе суда, если усматривается очевидное отклонение действий участника гражданского оборота от добросовестного поведения.

\section{Выводы}

В заключение рассмотрения вопросов злоупотребления интеллектуальным правом следует отметить, что факт злоупотребления может быть определен только судом, так как участники гражданских правоотношений равны между собой. Полагаем, что нормы о запрете недобросовестного поведения и злоупотребления правом адресованы в первую очередь суду. Важно, что сегодня возможность квалификации судом действий лица как злоупотребления не зависит от того, ссылалась ли другая сторона спора на злоупотребление правом противной стороной. Суд вправе по своей инициативе отказать в защите права лицу, злоупотребляющему им.

\section{СПИСОК ЛИТЕРАТУРЫ}

1. Гаврилов, Э. Комментарий к Постановлению Пленума Верховного Суда РФ и Пленума Высшего Арбитражного Суда РФ от 26 марта 2009 года № 5/29 «О некоторых вопросах, возникших в связи с введением в действие части четвертой Гражданского кодекса Российской Федерации» / Э. Гаврилов // Хозяйство и право. - 2009. - № 10. - С. 19-44.

2. Интеллектуальная собственность (права на результаты интеллектуальной деятельности и средства индивидуализации) / Н. М. Коршунов, М. В. Карпычев, Ю. Л. Мареев [и др.]. - М. : Норма, 2009. $-400 \mathrm{c}$.

3. Иншакова, А. О. Высокотехнологичные материалы как объекты интеллектуальной собственности в сфере межстранового инновационного сотрудничества РФ и США: правовой статус авторов и инвесторов / А. О. Иншакова, А. Я. Рыженков // Вестник Волгоградского государственного университета. Серия 5, Юриспруденция. - 2013. № 3 (24). - C. 9-20.

4. Иншакова, А. О. Охрана трансграничного оборота результатов интеллектуальной деятельности в контексте экономико-правовой интеграции РФ / А. О. Иншакова // Вестник Волгоградского государственного университета. Серия 5, Юриспруденция. - 2015. - № 1 (26). - С. 70-60.

5. Иншакова, А. О. Правовое регулирование интеллектуальной собственности в перечне законодательных приоритетов обеспечения наноиндустрии / А. О. Иншакова // Вестник Федерального арбитражного суда Северо-Кавказского округа. 2012. - № 1 (7). - С. 45-52.

6. Покровский, И. А. Основные проблемы гражданского права / И. А. Покровский. - М. : Статут, 2001. -353 с.

7. Харитонова, Ю. С. Залог исключительных прав в системе способов обеспечения исполнения обязательств / Ю. С. Харитонова // Вестник Волгоградского государственного университета. Серия 5, Юриспруденция. - 2015. - № 3. - С. 22-25.

\section{REFERENCES}

1. Gavrilov E. Kommentariy k Postanovleniyu Plenuma Verkhovnogo Suda RF i Plenuma Vysshego Arbitrazhnogo Suda RF ot 26 marta 2009 goda № 5/29 «O nekotorykh voprosakh, voznikhshikh v svyazi s vvedeniem v deystvie chasti chetvertoy Grazhdanskogo kodeksa Rossiyskoy Federatsii» [Review of the Resolution of the Plenum of the Supreme Court of the Russian Federation and Plenum of the Supreme Arbitration Court of the Russian Federation of March 26, 2009 № 5/29 “On Some Questions Arising in Connection 
with the Introduction of Part Four of the Civil Code of the Russian Federation"]. Khozyaystvo i pravo, 2009, no. 10, pp. 19-44.

2. Korshunov N.M., Karpychev M.V., MareevYu.L., et al. Intellektualnaya sobstvennost (prava na rezultaty intellektualnoy deyatelnosti i sredstva individualizatsii) [Intellectual Property (Rights to Results of Intellectual Activity and Means of Individualization)]. Moscow, Norma Publ., 2009. 400 p.

3. Inshakova A.O., Ryzhenkov A.Ya. Vysokotekhnologichnye materialy kak obyekty intellektualnoy sobstvennosti v sfere mezhstranovogo innovatsionnogo sotrudnichestva RF i SShA: pravovoy status avtorov $\mathrm{i}$ investorov [High-Tech Materials as the Objects of Intellectual Property in the Field of Intercountry Innovative Cooperation of the Russian Federation and the United States: the Legal Status of Sponsors and Investors]. Vestnik Volgogradskogo gosudarstvennogo universiteta. Seriya 5, Yurisprudentsiya [Science Journal of Volgograd State University. Jurisprudence], 2013, no. 3 (24), pp. 9-20.

4. Inshakova A.O. Okhrana transgranichnogo oborota rezultatov intellektualnoy deyatelnosti $\mathrm{v}$ kontekste ekonomiko-pravovoy integratsii RF [Protection of Transboundary Trafficking of the Results of Intellectual Activities in the Context of Economic and Legal Integration of the Russian Federation]. Vestnik Volgogradskogo gosudarstvennogo universiteta. Seriya 5, Yurisprudentsiya [Science Journal of Volgograd State University. Jurisprudence], 2015, no. 1 (26), pp. 70-60.

5. Inshakova A.O. Pravovoe regulirovanie intellektualnoy sobstvennosti $\mathrm{V}$ perechne zakonodatelnykh prioritetov obespecheniya nanoindustrii [Legal Regulation of Intellectual Property in the List of Legislative Priorities for Ensuring Nanotechnology Industry]. Vestnik Federalnogo arbitrazhnogo suda Severo-Kavkazskogo okruga, 2012, no. 1 (7), pp. 45-52.

6. Pokrovsky I.A. Osnovnye problemy grazhdanskogo prava [Main Problems of the Civil Law]. Moscow, Statut Publ., 2001. 353 p.

7. Kharitonova Yu.S. Zalog isklyuchitelnykh prav v sisteme sposobov obespecheniya ispolneniya obyazatelstv [Pledge of Exclusive Rights in the System of Ways of Obligations Execution]. Vestnik Volgogradskogo gosudarstvennogo universiteta. Seriya 5, Yurisprudentsiya [Science Journal of Volgograd State University. Jurisprudence], 2015, no. 3, pp. 22-25.

\section{Information About the Author}

Olga S. Avdonina, Degree-Seeking Student, the Department of Civil Law Disciplines, Moscow Academy of Economics and Law, Varshavskoe shosse, 23, 117105 Moscow, Russian Federation, avdoninaos@bk.ru.

\section{Информация об авторе}

Ольга Сергеевна Авдонина, соискатель кафедры гражданско-правовых дисциплин, Московская академия экономики и права, Варшавское шоссе, 23, 117105 г. Москва, Российская Федерация, avdoninaos@bk.ru. 